\title{
O PAPEL DA LÍNGUA PORTUGUESA NA COMPOSIÇÃO DE UMA ELITE POLÍTICA EM TIMOR-LESTE: SUBSÍDIOS PARA UMA DISCUSSÃO POLÍTICO- LINGUÍSTICA SOBRE LUSOFONIA
}

\section{THE ROLE OF PORTUGUESE LANGUAGE IN THE COMPOSITION OF A POLITICAL ELITE IN TIMOR-LESTE: SUBSIDIES FOR A POLITICAL-LINGUISTIC DISCUSSION ON LUSOPHONY}

\author{
Alexandre Cohn da Silveira \\ Doutorando no programa de Pós-Graduação em Linguística \\ Membro do Grupo de Pesquisa Políticas Linguísticas Críticas \\ E-mail: alexandretimor@gmail.com
}

\section{RESUMO}

O presente artigo busca discutir a relação entre a língua portuguesa e a formação de uma elite política na República Democrática de Timor-Leste (RDTL), a dos presidentes da república do período democrático. Trata-se de verificar como a língua portuguesa contribui para a constituição dessa elite após a guerrilha de resistência contra a Indonésia, bem como analisar possíveis contribuições que as relações estabelecidas pela língua (também relações de poder) trazem para a produção de um discurso favorável à presença da língua portuguesa no país. Para tanto, são analisadas as biografias oficiais três presidentes timorenses, a partir das quais um debate interdisciplinar é desenvolvido. De um lado, estudiosos da teoria das elites e da sociologia do poder, tais como Bourdieu (1983, 1989, 2015), Saint-Martin (2008), Coradini (2001, 2003), Seidl (2013), Codato (2008), Anjos (2006) e Dallabrida (2001) auxiliam o entendimento quanto à formação, à conversão e à manutenção das elites; e, de outro lado, os estudos das Políticas Linguísticas por Makoni e Meinhof (2006), Mariani (2004), Shohami (2006) e Rajagopalan (2003), permitem um entendimento pontual sobre discursos produzidos sobre a língua. O que se percebe é que a língua portuguesa, tal como aconteceu em outras ex-colônias lusitanas, foi acessada por uma pequena elite local de timorenses que possuíam contato direto com a metrópole e depois, dadas as circunstâncias políticas e de guerra que o país asiático vivenciou, a língua foi discursivizada como artefato político, constituindo um projeto nacionalista lusófono que nem sempre corrobora com as dinâmicas linguísticas do cotidiano.

Palavras-chave: Lusofonia. Elites Timorenses. Políticas Linguísticas

\begin{abstract}
This article aims to discuss the relationship between the Portuguese language and the formation of a political elite in the Democratic Republic of Timor-Leste (RDTL), the presidents of the republic in the democratic period. It is a question of verifying how the Portuguese language
\end{abstract}

Linguagens - Revista de Letras, Artes e Comunicação ISSN 1981-9943 Blumenau, v. 11, n. 1, p. 043-063, jan./abr. 2017 
contributes to the constitution of this elite after the guerrilla resistance against Indonesia, as well as to analyze possible contributions that the relations established by the language (also relations of power) bring to the production of a discourse favorable to the presence of the Portuguese language in the country. To do so, we analyzed three official biographies of Timorese presidents, from which an interdisciplinary debate is developed. On the one hand, scholars of the theory of elites and the sociology of power, such as Bourdieu (1983, 1989, 2015), Saint-Martin (2008), Coradini (2001, 2003), Seidl (2013), Codato (2008), Anjos (2006) and Dallabrida (2001) help understanding the formation, conversion and maintenance of elites; and, on the other hand, the studies of Linguistic Policy by Makoni and Meinhof (2006), Mariani (2004), Shohami (2006) and Rajagopalan (2003), allow a punctual understanding of discourses produced on the language. What is perceived is that the Portuguese language, as it happened in other former Lusitanian colonies, was accessed by a small local elite of East Timorese who had direct contact with the metropolis and then, given the political and war circumstances that the Asian country lived the language was discursive as a political artifact, constituting a nationalistic lusophone project that does not always corroborate with the linguistic dynamics of daily life.

Key-words: Lusophony. Timorese Elites. Language Policy.

\section{INTRODUÇÃO}

Timor-Leste, após proclamar sua independência de Portugal em 1974, foi invadido pela Indonésia no ano seguinte, vivendo um período de genocídio e imposições que transformaram significativamente as dinâmicas sociais do país. Os cidadãos que sobreviveram aos inúmeros massacres foram proibidos de usar a língua portuguesa em suas comunicações, sendo obrigados a assumir o idioma do invasor: o bahasal indonésio. Durante a invasão, a guerrilha de resistência utilizava, em muitas comunicações externas, a língua portuguesa, desconhecida do inimigo, o que fez com que o idioma recebesse a alcunha de "língua da clandestinidade" e "língua da resistência". Ao restaurar sua independência, em 2002, o pequeno país asiático optou por oficializar a língua portuguesa em parceria com o tétum, idioma nacional majoritário. Para tanto, muitos discursos foram construídos em defesa da oficialização do idioma do colonizador de outrora, evocando tradições, importância histórica e política e uma maior comunicabilidade com o resto do mundo.

Entretanto tais discursos possuem fragilidades e, no que tange a questões identitárias e políticas, as trajetórias de vida de leste timorenses de destaque nacional, como os presidentes da república do país, trazem à tona questões que problematizam os discursos oficiais em prol da língua portuguesa. Ao perceber a relação desses personagens com a língua portuguesa e a conversão do capital cultural relativo ao idioma em capital político, tornam-se evidentes alguns 
paradoxos acerca da oficialização do idioma no país, e que tem provocado alguns desajustes entre as políticas linguísticas estatais e as práticas linguísticas dos cidadãos timorenses. Acreditase que a pretendida identidade lusófona leste-timorense foi idealizada por discursos políticos outros, com intenções liberais e neocoloniais, os quais conduzem as políticas linguísticas in vitro do país que, por sua vez, não refletem as políticas in vivo2.

Uma vez que os três presidentes da República Democrática de Timor-Leste (RDTL) aqui analisados 3 possuem forte relação com os processos históricos de independência e luta de guerrilha vivenciados no país, a contextualização de situações sócio-histórico-políticas torna-se fundamental, tanto no que se refere à teoria das elites, quanto no que tange à produção de enunciados e ações discursivas pertinentes aos discursos analisados. Segundo Codato (2008, p.2) “Os contextos históricos desempenham um papel essencial não como 'pano de fundo' para as análises de elite, mas como o meio no qual eventos, agentes e processos estão, de maneira inelutável, inseridos". Também, segundo Bakhtin (1997, p.86) os enunciados existentes e situados sócio historicamente não podem "deixar de tocar os milhares de fios dialógicos existentes, tecidos pela consciência ideológica em torno de um dado objeto de enunciação", assim como não podem "deixar de ser participante ativo no diálogo social. Ele também surge desse diálogo como seu prolongamento, como sua réplica (...)"

Nessa orientação epistemológica, primeiramente o artigo situa teoricamente o conceito de "elite" e sua vertente política, a partir do campo da chamada Sociologia do Poder. Em seguida, as biografias dos três presidentes são analisadas a partir de critérios escolhidos por evidenciarem o possível contato dos personagens com a língua portuguesa na formação de uma elite política timorense: a família, a escolarização e a trajetória profissional/política. Com base nas informações biográficas, a terceira parte deste estudo procura entender como a língua portuguesa pode ter contribuído para a formação de uma elite política presidencial timorense, assim como verifica as construções discursivas feitas sobre o idioma dentro de um projeto de nação pretendido. Por fim, uma tentativa de finalização desta ampla discussão é apresentada em termos de considerações finais.

\section{INÍCIO DE CONVERSA}

O termo "elite" refere-se, ainda que de forma generalizada e imprecisa, aos indivíduos pertencentes a grupos em destaque na estrutura social e, segundo os estudos iniciais de Mosca (1963), Pareto (1963) e Michels (1971), o termo emerge a partir das características de uma minoria que detinha o poder político e econômico, sendo mais tarde radicalizado com a noção de 
classe dominante oriunda do marxismo. Com Mills (1959), essa noção é reforçada com as proposições do autor sobre grupos no poder, em especial grupos militar, político e econômico. Ainda que o Estado seja um dinamizador de forças políticas (BOURDIEU, 2015), há uma relativa autonomia política no que diz respeito à produção cultural, seja científica, literária ou artística, a qual, aliada aos processos históricos, servem de base para formulação conceitual, inclusive para a noção de "campo" a qual, de acordo com Bourdieu (1983), pressupõe a existência de um plano com sua lógica e dinâmica peculiar, bem como princípios de concorrência e hierarquização próprios, no qual coexistem e se relacionam sujeitos distintos com recursos sociais característicos e tomadas de posição conduzidas pela ideologia dominante. (MONTEIRO, 2009)

Novamente segundo Bourdieu (1983), o campo é o espaço de práticas específicas, com relativa autonomia e com uma história peculiar, organizado em um espaço de possibilidades, que visa a busca por agentes que o conduzam e que definem suas dinâmicas peculiares, numa espécie de "jogo". No âmbito das relações de forças específicas e das lutas que as conservam ou transformam, são arquitetadas as estratégias necessárias para seus produtores agirem, os discursos e interesses que defendem, as alianças que estabelecem, as escolas que fundam e isso por meio dos interesses específicos que aí são determinados. O capital econômico, o capital simbólico e o capital cultural que os agentes possuem são fundamentais para estabelecer a posição de dominantes e dominados em um campo (BOURDIEU, 1983, p. 61).

Quanto a possíveis delimitações entre as diferentes elites, seus agentes e instituições, Saint Martin (2008) esclarece que os espaços ocupados pelas elites são vários, abrangendo posições de poder político, administrativo, econômico, militar, cultural, religioso, entre outros. Segundo a pesquisadora, as fronteiras dessas elites são nebulosas, o que dificulta qualquer definição mais precisa sobre seus grupos dirigentes ou outras classificações, na opinião da autora, desimportantes. Conforme a autora, as elites não se constituem em um grupo de sujeitos ocupantes das posições de destaque nos âmbitos político, econômico e administrativo, ou caracterizando uma categoria da estratificação social, mas sim "elas [as elites] propõem modelos de comportamento, possuem sistemas de valores e interesses, constituem grupos de influência e, às vezes, de pressão.” (p.48-49)

Segundo Coradini (2001), apesar de uma progressiva centralização das decisões políticas, as "problemáticas legítimas” dos âmbitos decisórios envolvem "diretamente processos que abrangem esferas e instituições específicas, tais como igrejas, sistema escolar, forças armadas(...)" (ibidem, p.126). O autor, questiona as relações dessas problemáticas com as "condições sociais de sua geração e na reconversão de recursos sociais e culturais entre esses 
universos sociais" uma vez que, além dos fatores de capital contribuintes para o processo, podem participar outros recursos que considera igualmente importantes, tais como “(...) a respectiva posição nas relações centro/periferia e, ainda, nas classificações étnicas, que, por sua vez, podem aparecer como condição, ou, então, se constituir em recorte de elaboração identitária" (ibidem, p.127). Daí a importância da atuação, em territórios colonizados, dos sujeitos que agem como "mediadores" entre as metrópoles e as instituições coloniais, tanto nas questões culturais, quanto no que tange à política e à burocracia pública. Sujeitos esses que, conforme Anjos (2006), vieram a constituir a chamada "elite intelectual e política" do território colonial.

Importa-nos, nesse estudo, entender a constituição e o processo de legitimação dos ditos "mediadores" pertencentes a uma esfera política, entendendo a sua composição social, os recursos culturais constituintes e os itinerários profissionais dos membros mais destacados da elite política, seu "desenvolvimento político" (CODATO, 2008). Isso convida a concentrarmos nossa análise em uma elite específica, dentro do que pode ser entendido como elite política: a dos presidentes da república. Seguindo Coradini (2001) busca-se focar não os indivíduos, mas “os recursos e princípios de legitimação que estruturam suas práticas" (p.13), em especial neste caso, por serem os membros da elite política que mais se destacam publicamente.

Parte-se dos dados presentes nas biografias oficiais dos presidentes da RDTL por serem fontes de dados de fácil acesso, públicas, oficiais e divulgadas com a autorização de seus protagonistas e por contemplarem as categorias escolhidas para análise, a saber: escolarização, capital social e cultural, trajetória profissional e política, e organização familiar. As biografias são, constantemente, fontes de dados para estudos de elites (HEINZ, 2011) e apresentam informações as quais, muitas vezes, permitem alcançar a história social, a trajetória política, a carreira, a construção da imagem social e política e outras variáveis para a compreensão da formação da elite estudada (CODATO, 2008). Entretanto Heinz (2011) destaca que as biografias também pecam ao omitir ou manipular informações dando enfoque excessivo em uma parte da vida ou da experiência profissional do biografado em detrimento de outros momentos de sua trajetória, ou ainda, informações-chave relativas à ascensão ou reconversão profissionais apresentadas de forma sucinta, ou questionáveis frente a outras bases de dados. Heinz declara que o que importa "É aquilo que um representante político ou líder sindical tem em comum (ou em que ele difere) com o conjunto dos membros do grupo, os elementos que nos ajudam a compreender o sentido de sua trajetória." (p.159) Sendo assim, o "discurso sobre si” é, em geral, "produção de si", algo que é feito para atender à necessidade a que se dispõe, seja pessoal, político-ideológica ou de outra sorte, sobretudo em se tratando de personagens públicos e de destaque internacional. 


\section{UMA POSSÍVEL ELITE TIMORENSE: OS PRESIDENTES DO PERÍODO DEMOCRÁTICO}

A análise das trajetórias de vida dos três presidentes da República Democrática de Timor-Leste do período pós-Indonésia - Xanana Gusmão (2002-2007), José Ramos-Horta (2007-2012) e Taur Matan Ruak (2012) - será pautada em três critérios (origem e família, escolarização, trajetória profissional e política) escolhidos entre os diversos que permeiam as pesquisas nos estudos da Teoria das Elites, com o intuito de melhor focar o objeto desta discussão, seguindo a ordem dos mandatos de cada presidente.

\subsection{ORIGENS E FAMÍLIA}

A primeira categoria analisada leva em conta a origem de cada presidente, sua infância, seus pais e a profissão destes, ou seja, o legado familiar e a herança de berço que cada um porventura tenha recebido. Seidl (2013) destaca que o legado familiar representa fator de peso “de mecanismos de formação e manutenção de grupos dirigentes" (p.199), sendo isso mais evidente em países periféricos, inda que não exclusivamente nesses.

Segundo Niner (2011), Xanana Gusmão, cujo nome de batismo é José Alexandre Gusmão, foi presidente timorense do período 2002-2007, nasceu no distrito de Manatuto, leste do país, no dia 20 de junho de 1946, onde viveu sua infância com seus pais e outros seis irmãos. A biógrafa diz que, embora a família não pertencesse às camadas sociais mais pobres, não gozavam de regalias: a mãe não tinha profissão formal, se ocupando da casa e da família, e o pai era professor em escolas de nível primário e secundário, o que lhe conferia um estatuto social mais valorizado à época. Segundo Niner, a família de Xanana vivia em condições melhores que a maioria da população local. Devido à profissão do pai, havia um incentivo à educação dos filhos, diferentemente do que acontecia (e ainda acontece) na maioria das famílias, cujas crianças nascidas em cidades do interior são preparadas para os trabalhos rurais. Teve, por conta do pai, acesso facilitado a livros e estudos que o permitiram ampliar conhecimentos e expandir ideias com mais facilidade, além de ser socializado no universo católico, em língua portuguesa e de hábitos europeus. Aos 12 anos, Xanana mudou-se para Dare, região serrana perto da capital do país, Díli, para estudar no Seminário Nossa Senhora de Fátima.

O segundo presidente do período democrático (2007-2012), José Manuel Ramos-Horta, nasceu em 26 de dezembro de 1949, na capital de Timor-Leste, Díli. Sua biografia disponível na Embaixada de Timor-Leste, em Brasília, traz informações sobre a família numerosa do presidente, composta por 11 filhos de mãe timorense e pai português, exilado na antiga colônia 
de Timor pela ditadura de Salazar. Antes disso, já o seu avô havia sido exilado de Portugal, nos Açores, Cabo Verde e, finalmente, em Timor, segundo os registros oficiais. Horta viveu sua infância e adolescência em meio urbano, na capital do país e, apesar de sua mãe também ser responsável pela organização doméstica, o pai, comerciante, tinha grande interesse pelas questões políticas da época. $\mathrm{O}$ fato de ter um pai português trouxe para a dinâmica familiar costumes europeus e uma visão de mundo diferente da que seus companheiros políticos possuíam. Dos três presidentes foi o que melhores condições de vida possuía em termos de capital material e imaterial, o que fica evidente nas palavras de Xanana Gusmão (2006) quando descreve Ramos-Horta dizendo que ele “(...) era mais, como dizíamos, "selecto”, com ar sui generis de assimilado ${ }^{4}$ intelectual(...)" (p.xxv)

A biografia de José Maria de Vasconcelos, conhecido por Taur Matan Ruak, o terceiro presidente da RDTL (2012-2017), também disponível na Embaixada de Timor-Leste e no site da Presidência da RDTL $^{5}$, omite maiores detalhes sobre a infância e a adolescência do político. Segundo os registros, Matan Ruak nasceu em 10 de outubro de 1956, no inóspito povoado de Ossu Huna, perto de Baguia, no distrito de Baucau, região leste do país. Seus pais eram agricultores, de vida humilde e parcas condições financeiras para criar os nove filhos. Isso fez com que ele fosse levado a viver com um tio na capital do país já aos quatro anos de idade, ainda que em condições de pobreza, mas com possibilidades de sobrevivência e melhores recursos. Ruak foi o menos privilegiado dada as condições de extrema pobreza e falta de oportunidades no seio da família para que informações e conhecimentos, para além da antiga colônia da Timor, chegassem a despertar seus interesses.

Retomando Seidl (2013), se "o fato de um grupo familiar, ao longo de gerações, ter-se mantido em situação dominante (...) implica o acúmulo de um capital de notoriedade ligado (...) à "tradição" de estar em posições de prestígio (...)" (p.199), o caso de Timor-Leste, certamente por ter atravessado um longo período de dominação e guerra, revela que essa "tradição" talvez seja construída nas próximas gerações a partir desse momento de formação das elites pósconflito. O que se percebe é que o valor simbólico de estar ligado à história de lutas do país, possui um peso maior no recrutamento da elite política timorense do que apenas o capital familiar.

\subsection{ESCOLARIZAÇÃO}

Há diversos estudos sobre as elites dos mais variados contextos que destacam a importância do processo de escolarização, muitas vezes como um fator determinante na formação das elites (SAINT MARTIN, 2008; DALLABRIDA, 2001; CANÊDO, 2013; entre 
outros), especialmente das elites políticas, com seus dispositivos de exclusão e seleção bem definidos. Ainda que em contextos diferentes e peculiares, os estudos citados mostram que o acesso às informações, os dispositivos didático-curriculares e as "heranças" e capitais culturais diversos adquiridos são decisivos na formação das elites, o que em Timor-Leste não é diferente.

Por conta das diferenças entre as origens familiares de cada um, os presidentes possuíram histórias de escolaridade e formação também diferentes entre si. É importante destacar que, no período do Timor português em que os três cresceram, Portugal quase não investia em educação na colônia, ficando isso a cargo da Igreja, sobretudo dos jesuítas e as madres canossianas $^{6}$. As primeiras instituições de ensino foram fundadas por missionários no século XVIII e, conforme Meneses (2008), em meados da década de1960, a Igreja controlava 60\% da instrução primária. As melhores escolas eram de organização católica e as poucas escolas públicas sobreviviam com um mínimo de recursos, salas multisseriadas por conta da escassez de professores e nenhum material didático ${ }^{7}$. O ensino superior era inexistente em Timor $^{8}$, o Liceu Dr. Francisco Vieira, bem como as escolas profissionalizantes e rurais ofereciam cursos que garantiam a condição colonial e que não favoreciam o acesso a todos, dadas as "propinas" a serem pagas. Uma opção que garantia formação de alto nível eram os seminários, para os rapazes, e os conventos, para moças, o que reforçava a importância da Igreja no projeto colonial e desobrigava a metrópole portuguesa de ampliar investimentos que poderiam vir a ser prejudiciais aos interesses portugueses. (MENESES, 2008)

Xanana Gusmão teve seus estudos iniciais em Ossu, zona rural do país, na Escola Primária Santa Teresa e, de acordo com Niner (2011), dos 12 aos 18 anos de idade estudou no Seminário Nossa Senhora de Fátima, em Dare, região de montanha perto da capital do país, Díli. Aos 18 anos teve diversos empregos em Díli, mantendo seus estudos à noite no Liceu Dr. Francisco Vieira. Entretanto, os registros biográficos de Xanana na Embaixada de Timor-Leste mostram que, por problemas financeiros, o presidente teve que suspender os estudos por 3 anos, retomando-os em 1966. Não possui nenhum diploma universitário, em virtude da vida com recursos limitados e pelo envolvimento com as questões políticas e de guerrilha.

O presidente Horta frequentou a Escola Católica de Soibada, tendo recebido sólida formação intelectual e também espiritual, a ponto de isso ter convergido para uma carreira no sacerdócio católico. Fez seus estudos secundários em Díli, no Liceu Dr. Francisco Vieira e ingressou no jornalismo local, dada a falta de opções de formação superior no país. Entretanto, de acordo com os registros oficiais, sua postura anticolonialista fez com que fosse deportado para Moçambique onde residiu por dois anos (1970-1971) ${ }^{10}$. Retorna a Timor-Leste e participa ativamente da campanha pró-independência, tendo saído do país dias antes da invasão indonésia. Durante os anos no exílio, no período da invasão, Horta atuou externamente na luta de 
resistência, paralelamente aumentou seu capital intelectual através de sua formação acadêmica. Estudou Direito Público Internacional na Academia de Direito Internacional de Haia (1983) e na Universidade de Antioch (EUA), onde completou um mestrado em Estudos sobre a Paz (1984). Os registros biográficos destacam que Horta recebeu instrução também na área dos direitos humanos no Instituto Internacional de Direitos Humanos em Estrasburgo, França (1985). Frequentou o curso de pós-graduação em Política Externa Americana na Universidade de Columbia, Nova Iorque (1986), e é Associado Sénior do St. Anthony College, Oxford, Inglaterra (1987). Em 1998, Ramos-Horta frequentou a Escola do Governo John F. Kennedy, na Universidade de Harvard, onde completou o Programa Executivo para Líderes em Desenvolvimento

Os registros sobre a escolaridade de Taur Matan Ruak limitam-se a dizer que o presidente não concluiu a educação básica, tendo finalizado seus estudos ao fim do nível primário, o que é uma consequência das limitações familiares e financeiras. Sendo o mais novo dos três presidentes, vivenciou a guerra contra à Indonésia desde sua adolescência, não havendo oportunidade para qualquer escolarização. Durante a guerra contra a Indonésia, Matan Ruak ficou em solo timorense, comandando as tropas de guerrilha e sobreviveu aos anos de combate e vida precária na floresta, restringindo sua formação ao exercício militar e de guerrilha. (CARRASCALÃO, 2012)

A discrepância entre a formação escolar dos três presidentes é enorme. Os "privilégios" de que Ramos Horta desfrutou no exílio, influenciados pelos contatos que seu pai possuía, se aliaram às orientações de esquerda política, iniciadas no âmbito doméstico e acentuadas nos ambientes escolares que frequentou. Xanana Gusmão, a seu turno, teve alguns incentivos, ainda que limitados, e conseguiu adquirir formação intelectual bem acima da média nacional timorense, o que lhe abriu portas sociais relevantes para sua vida política. Já Matan Ruak, não usufruindo de quaisquer privilégios, na Força Clandestina construiu sua formação no âmbito militar.

Dallabrida (2001) destaca que "as escolas frequentadas pelas elites tendem a transmitirlhes os 'saberes nobres', capitais culturais que contribuem para a produção estética e a manutenção do 'status' das classes dominantes."(p.26) Sendo Timor ainda uma colônia portuguesa quando os três estavam no ensino básico, a ideologia portuguesa colonial permeava os currículos buscando a manutenção da condição subalterna de Timor frente à metrópole portuguesa no sentido de conservar o que estava politicamente estabelecido. Xanana - por circular nos ambientes da administração da colônia - e Horta - principalmente por conta de seu pai - tiveram acesso a livros e pessoas de orientação marxista o que lhes despertou o caráter revolucionário em favor de um movimento nacionalista. Dos três, Ramos-Horta teve 
oportunidade de dar continuidade à sua formação acadêmica na diáspora. Dessa forma, os processos de "aprendizagem total" e "aprendizagem tardia" (BOURDIEU apud DALLABRIDA, 2001, p.28) constituem-se de forma peculiar entre os três: enquanto Xanana, em menor escala, e principalmente Horta acumulam aprendizagens e capital cultural desde sua família aprendizagem total -, Ruak possui um gap em sua formação escolar, só vindo a retomar alguns estudos particularmente após a restauração da independência do país - aprendizagem tardia.

\subsection{TRAJETÓRIA PROFISSIONAL E POLÍTICA}

Os caminhos profissionais dos presidentes também são distintos, convergindo para a política de formas igualmente diferentes, porém com um ideal comum que perpassa suas histórias de vida: a luta nacionalista da resistência contra a Indonésia e a independência de Timor-Leste. Horta e Xanana, principalmente, atuaram (e ainda atuam) como mediadores culturais, modalidade “(...) que é exercida pelo grupo local que detém a exclusividade de desempenho dos códigos metropolitanos (desde a língua, passando pelo jurídico, literário, etc).” (ANJOS, 2006, p.31)

Xanana Gusmão ingressou na administração pública colonial para custear seus estudos, atuando como funcionário público português, o que logo lhe trouxe destaque no ambiente profissional, segundo Niner (2011), em virtude do grande domínio da língua portuguesa e pela facilidade e desenvoltura com a escrita, fato que também lhe rendeu alguns trabalhos como jornalista. Dado o seu gosto pela prática de esportes desde os tempos de escola e seminário, foi recrutado, em 1968, para o exército português, onde serviu por três anos, chegando à posição de cabo. Também trabalhou formalmente como jornalista no Jornal "A Voz de Timor", escrevendo artigos de cunho político de esquerda e poemas. Seu envolvimento com a política deu-se a partir da Revolução dos Cravos, em 1974, quando ele e outros jovens timorenses vislumbraram a possibilidade de tornar Timor independente, tal como aconteceu com as demais ex-colônias portuguesas. Ele aderiu à recém-formada Associação Social Democrata (ASDT), a qual, no mesmo ano, transforma-se no que veio a ser o partido proclamador da independência de TimorLeste, mantenedor das forças de guerrilha durante a ocupação indonésia e, até hoje, a mais estruturada e atuante organização política de esquerda no país: a Frente Revolucionária de Timor-Leste Independente (FRETILIN).

De acordo com a sua biografia, Gusmão assumiu a função de Diretor Adjunto do Departamento de Informação. Durante a ocupação da Indonésia, e após o presidente da FRETILIN ter sido assassinado, assim como aconteceu aos principais membros do Comitê Central do partido que estavam em solo timorense, Xanana foi incumbido de reorganizar a luta 
pela libertação de Timor-Leste. Foi "eleito" Líder da Resistência e Comandante Chefe das Forças Armadas de Libertação Nacional de Timor-Leste (FALINTIL), em uma manobra política $^{11}$ conhecida nomeadamente por Primeira Conferência Nacional da FRETILIN.

Durante a guerra de resistência, conseguiu um "cessar fogo" com as forças indonésias através de negociações que conduziu com habilidade tendo criado e implementado a Política de Unidade Nacional, envolvendo autoridades tradicionais de Timor-Leste e membros da Igreja Católica e desenvolveu a Frente Clandestina que veiculava informações no território nacional e entre os ativistas exilados. Em 1988, a Política de Unidade Nacional deu lugar à criação do Conselho Nacional de Resistência Maubere (CNRM), mais tarde Conselho Nacional de Resistência Timorense (CNRT), atual partido político de Xanana. Quando preso, na Indonésia, recebeu visita de pessoas de destaque internacional, como Nelson Mandela, o que auxiliou à visibilidade da causa de Timor e reforçou o estatuto de liderança de Gusmão. Xanana Gusmão, valendo-se dos espaços midiáticos e de sua proximidade com a administração pública, além das jogadas políticas implementadas (MATTOSO, 2005), assumiu a postura de líder dos interesses do povo timorense, construindo respeitabilidade junto aos conterrâneos. Sua formação escolar e as relações políticas que estabeleceu durante a guerra de resistência à Indonésia também favoreceram sua posição de Comandante-Chefe das forças de guerrilha, garantindo autoridade junto aos soldados e sendo temido pelo governo Indonésio.

Ramos Horta, a seu turno, começou a trabalhar como jornalista quando ainda estudava no Liceu. Já era, nessa época, amigo de Xanana Gusmão, segundo sua biografia oficial, com quem, juntamente com outros jovens, participava de encontros que debatiam política e a situação colonial de Timor. Ativista em diversos movimentos revolucionários pela liberdade de Timor foi obrigado a sair do país, tendo o primeiro exílio político em Moçambique. Ajudou a fundar a FRETILIN, em 1971, quando retornou de Moçambique e, em 1975, estava no grupo liderado por Francisco Xavier do Amaral - proclamador da independência do país - tendo sido nomeado Ministro dos Negócios Estrangeiros. Dias antes da invasão indonésia, conforme expõe Taylor (1993), Horta deixou o país para levar o caso timorense à sede das Nações Unidas em Nova Iorque, requisitando uma ação imediata da organização em favor do país e do povo de TimorLeste, fato entendido como "fuga" por muitos timorenses que permaneceram no país em conflito.

Além da construção de sua carreira acadêmica, Ramos-Horta se ordenou sacerdote católico em julho de 1980, além de ter trabalhado na Embaixada de Moçambique nos Estados Unidos, entre 1987 e 1988. Em 1992, quando da prisão de Xanana Gusmão, Horta assumiu a posição de único porta-voz timorense no exterior para denunciar a violência indonésia em Timor-Leste, inclusive apresentando um plano de paz diante do Parlamento Europeu em busca do respeito aos direitos humanos, o fim do conflito armado e a anistia aos presos políticos, bem 
como uma intervenção das Nações Unidas, no sentido de organizar um referendo junto ao povo timorense para que este decidisse o que seria melhor para o país. A partir de 1992, Ramos Horta se dividiu entre Sidney (Austrália) - onde lecionou Diplomacia na Faculdade de Direito da New South University - e Lisboa, também atuando como delegado de direitos humanos das minorias, da ONU, até retornar a Timor-Leste, em 2000. Ramos-Horta representou relevante papel nas relações exteriores entre as forças nacionalistas e a comunidade internacional, dada a fácil circulação que possuía no ambiente acadêmico, religioso e político (MATTOSO, 2005). O alto conhecimento sobre diplomacia e direitos humanos construíram uma imagem de sensatez e confiança tanto para o povo timorense, quanto para a opinião pública estrangeira.

A trajetória profissional e política de Taur Matan Ruak tem início, segundo sua biografia oficial, a partir da invasão indonésia quando, com 19 anos, ingressou na recémformada FALINTIL - Forças Armadas de Libertação e Independência de Timor-Leste, as forças armadas da FRETILIN - indo para os esconderijos da resistência nas montanhas do país. Foi combatente presente nas principais batalhas pela libertação e começou a assumir posições de comando em 1976. Destacou-se pela forte característica de liderança e, por ser grande estrategista, assumiu progressivamente o comando da Força de Resistência até 1979, quando foi capturado pelo exército indonésio. Entretanto, conseguiu escapar do campo de prisioneiros de guerra após 23 dias, retornando às tropas timorenses e a seu progresso no comando das ações militares, até que assumiu a responsabilidade total pelas operações de guerrilha em 1986. Por ocasião da prisão do Comandante Chefe, Xanana Gusmão, em 1992, Matan Ruak também assumiu esse posto até o final da guerra de resistência. Em 2001, já no período do governo de transição da ONU, o então Comandante Chefe da FALINTIL, Matan Ruak, foi nomeado Comandante da Força de Defesa de Timor-Leste na posição de General-Brigadeiro. Ruak é o presidente de menor formação escolar e experiência política dentre os três aqui analisados, sobretudo por ser mais jovem. Ocupou espaço relevante na luta armada, destacando-se pelo espírito de liderança e pelo estrategista de guerra que se revelou ao longo dos 24 anos de guerra pela libertação do país. (CARRASCALÃO, 2012)

\section{A LÍNGUA PORTUGUESA NA FORMAÇÃO DA ELITE POLÍTICA PRESIDENCIAL TIMORENSE}

Sendo a língua, segundo Makoni e Meinhof (2006), "uma invenção, uma construção" (p.193) o processo de organização dessa criação dá-se por ações discursivas imbricadas nas situações sócio históricas, o que, de acordo com Bakhtin/Volochinov (1929, p.123), consiste em "parte integrante de uma discussão ideológica em grande escala" que "responde a alguma coisa, 
refuta, confirma, antecipa as respostas e objeções potenciais(...)”. O processo de discursivização sobre uma língua atende também a intenções políticas, as quais deflagram uma série de questionamentos quanto às intenções e consequências desses discursos. Bo caso da oficialização de um idioma - como acontece em Timor-Leste - questões e conflitos provenientes das políticas linguísticas estatais adotadas eclodem afetando incisivamente a vida dos cidadãos (CALVET, 2005). Por trás da máscara de um nacionalismo pretendido existem armadilhas e artimanhas políticas que merecem cuidadoso olhar crítico.

O passado colonial timorense não apresenta esforços significativos quanto à uma suposta necessidade da língua portuguesa no país, a não ser aos que acessavam o funcionalismo público, para servir ao governo português. Como dito antes, Portugal pouco se empenhou no que tange à Educação, que coube quase que totalmente à Igreja e seus interesses próprios. Após a restauração da independência, o governo de Timor-Leste oficializa constitucionalmente o idioma lusitano e cria mecanismos ${ }^{12}$ para uma valorização social e política quanto ao uso da língua portuguesa. Nessa construção do Estado timorense, o idioma, então, recobra um estatuto de prestígio sobre as mais de 20 línguas das etnias timorenses - o que acontecia no período colonial - ainda que continue praticamente restrito aos ambientes administrativos ${ }^{13}$. Nas escolas públicas, o português é idioma de ensino e disciplina curricular, juntamente com o tétum. Entretanto aparece precariamente em enunciados escritos nas lousas ou nos raros materiais didáticos disponíveis aos alunos enquanto que as explicações orais são dadas em língua tétum, também idioma oficial nacional, ou em língua indonésia e até mesmo em língua inglesa, línguas determinadas como "línguas de trabalho" na Constituição da República ${ }^{14}$. Vale lembrar que, de acordo com Makoni e Meinhof (2006), a "objetivação da língua encoraja aqueles que elaboram políticas a pensar em termos de que as pessoas possuem línguas, ou de quantas pessoas podem ser persuadidas a usá-las” (p.195). Também, segundo Mariani (2004), a objetivação de línguas é um preceito colonial, ou de um colonialismo linguístico, no qual discursos são usados sobre as línguas, instituindo lugares e funções para elas, "a partir de um domínio de saber linguístico, alimentado por um imaginário já pré-constituído, ao mesmo tempo em que passa a fomentar o saber sobre as línguas e a circulação de outros sentidos não previstos. ” (p.29)

Nesse aspecto, Timor-Leste vive um cenário de dissonâncias entre as políticas estatais e as práticas linguísticas cotidianas, o que nos leva a refletir quanto às razões que movem as políticas linguísticas adotadas. Um dos discursos em defesa da presença do idioma colonial na construção do Estado-nação timorense reside na suposta tradição que permeia o passado do país e sua relação com Portugal. Apesar das ações políticas revolucionárias de resistência que restauraram a independência de Timor-Leste, a orientação de atrelar língua à construção do 
Estado em nada se assemelha ao caráter revolucionário de "nação", o qual, segundo Hobsbawn (2013) não busca o vínculo coletivo de seus membros a partir de categorias como a etnia ou a língua. $\mathrm{O}$ autor explica que o que constrói uma nação, do ponto de vista revolucionário, é "o fato de ela representar o interesse comum contra os interesses particulares e o bem comum contra o privilégio." (p.33) Hobsbawn afirma que a categoria "língua" é levada em conta na formação de uma nação sob orientação liberal capitalista, inserida em critérios de seleção, tais como: a associação histórica com outro Estado existente; a existência de uma elite cultural estabelecida, com vernáculo administrativo e literário e; comprovada capacidade para conquista (HOBSBAWN, 2013, p. 53). Reforça ainda o autor dizendo que "a identificação nacional era (...) fortemente linguística, mesmo que (...) a língua nacional fosse falada diariamente por mais do que uma pequena minoria (...)". Mariani (2004, p.25) complementa dizendo que a "colonização linguística (...) supõe a imposição de ideias linguísticas vigentes na metrópole e um imaginário colonizador enlaçando língua e nação em um projeto único. " Seguindo essas reflexões, percebese que uma elite constituída, assim como seu processo de recrutamento e seleção constitutivos, coaduna com um projeto de Estado liberal no qual a língua representa capital simbólico relevante.

Retomando a trajetória dos presidentes timorenses, Xanana Gusmão aprendeu o idioma lusitano com o pai e ampliou seus conhecimentos nas escolas que frequentou tendo isso consolidado sua carreira na administração pública, onde o idioma veicular necessariamente era o português. Xanana também era dado às artes: na literatura, escreveu um livro de poesia Mar Meu, além de Timor-Leste: Um povo, uma pátria e Xanana Gusmão: e os primeiros 10 anos da construção do Estado timorense. Também pintou quadros, muitos dos quais vendidos para a manutenção das tropas de resistência. Sua figura quase que mitológica, recebeu vários reconhecimentos internacionais. ${ }^{15}$

O nome do presidente participa da construção simbólica feita em torno de sua imagem, tanto junto a seu povo, quanto no cenário internacional, refletindo preocupações linguísticas identitárias peculiares. Apesar do nome de registro (José Alexandre Gusmão), é conhecido como Kay Rala Xanana Gusmão, em que Xanana seria um apelido (referente a Alexandre) ${ }^{16}$ ou o nome do avô de Gusmão, segundo Costa (2014). ${ }^{17}$ O fato é que uso do nome Kay Rala Xanana Gusmão possui uma força social e política muito intensa, sendo respeitado por todo o povo timorense, mesmo por aqueles que se opõem politicamente ao líder. Niner (2011, p.19) adiciona que o nome "simboliza a sua identidade híbrida, a sua reclamada ascendência indígena combinada com um estilo pessoal único e moderno, sublinhado por uma herança portuguesa profundamente sentida." (grifos meus) 
José Ramos-Horta é filho de português e sempre teve estreita relação com Portugal e com os países da CPLP - Comunidade dos Países de Língua Portuguesa. Sua educação mais requintada proporcionou-lhe destaque internacional e sua luta nacionalista o que é entendido como uma grande oportunidade para que o mundo soubesse o que se passava em Timor. ${ }^{18}$. A língua portuguesa esteve sempre presente em sua vida pessoal, política, religiosa e cultural. Horta também recebeu reconhecimento internacional ${ }^{19}$, tendo inclusive sido laureado, em 1996, com o prêmio Nobel da Paz, o que concorreu significativamente para trazer à tona a causa de Timor no cenário internacional.

Taur Matan Ruak possui uma história de vida bem distante da língua portuguesa, tanto pelas questões familiares quanto pela baixa escolaridade. Nas comunicações clandestinas como guerrilheiro usava a língua tétum e, algumas vezes, sua língua materna, o makassae. Veio a estudar o português após a restauração da independência da RDTL, em 2002, e pouco usa o idioma em seus pronunciamentos. (CARRASCALÃO, 2012) Em 2010, o então general e comandante das FALINTIL, deu uma entrevista em que defende a ideia de ser a língua tétum "a língua nacional de Timor-Leste" e a única que deveria ser usada, por exemplo, nos tribunais timorenses. A língua portuguesa, na opinião do general à época, seria uma língua "de apoio" para "comunicação com os estrangeiros". ${ }^{20}$ Entretanto, a partir do momento que assume a presidência da república, Matan Ruak assume o discurso oficial em defesa do idioma. O presidente publicou um artigo intitulado “A importância da língua portuguesa na sua resistência contra a ocupação indonésia" 21 , em que, por meio da ligação entre o idioma e a guerrilha, estabelece um estatuto de importância histórica para a língua portuguesa, a qual deve ser reconhecida e valorizada. Recentemente, em 26 de janeiro de 2016, o presidente da Indonésia, Joko Widodo, fez sua primeira visita oficial a Timor-Leste, sendo recebido pelo presidente Ruak, que discursou em língua portuguesa. ${ }^{22} \mathrm{O}$ fato causou impacto pois, apesar da falta de traquejo que o presidente tem com o idioma, uma posição política institucional foi demarcada, ou remarcada, através do uso oficial do idioma. Destaca-se que Ruak, em seus discursos, normalmente se pronuncia em língua inglesa, quando em contato com autoridades estrangeiras ${ }^{23}$. Assim como Xanana, o nome Taur Matan Ruak tornou-se mais conhecido que o nome de batismo do presidente por conta da tradição de guerrilha construída pelo uso do então codinome, que, em língua tétum, significa "dois olhos vivos" (atentos). Definitivamente seu maior capital social está ligado à sua liderança e espírito estratégico que o fez galgar postos de destaque na luta armada. 
Diante das informações apresentadas, percebe-se que a língua portuguesa foi, na vida dessas três personagens, um elemento de prestígio social, que foi acessada já no seio familiar (caso de Xanana e de Horta). No tempo do Timor colonial, o conhecimento da língua portuguesa favoreceu uma inserção no mercado de trabalho - funcionalismo público, jornalismo - bem como possibilitou o conhecimento da arte literária e dos escritos políticos. Após a guerra, os timorenses retornados que tinham o conhecimento do idioma lusitano constituem uma elite intelectual e política que vem a decidir pela oficialização da língua portuguesa no país, tendo como uma das justificativas o passado histórico vivido por Timor-Leste e uma suposta identidade lusófona. Essa afirmativa, na realidade, mascara ideais políticos outros, dada a distância entre o idioma português e os timorenses de hoje, com todo esforço governamental e toda ajuda internacional no sentido de reforçar o espaço lusófono pretendido no país. Com recursos muito menores aliado à falta de interesse do governo português à época, o Timor colonial evidentemente apresentava uma distância ainda maior do idioma, agravado pelo fenômeno colonialista em nada agradável, independentemente de seu contexto de manifestações. O idioma foi "chave-de-acesso" daqueles que pretendiam penetrar no sistema dominante e buscar meios revolucionários contrários às imposições coloniais.

Ainda que com alguma afetividade com o idioma, advinda de laços familiares, não era a língua portuguesa que estabelecia as relações sociais e as práticas comunicativas cotidianas urbanas, muito menos as rurais, em maior proporção no país de maioria populacional rural. O idioma foi língua usada pelas forças clandestinas por ser de total desconhecimento dos soldados indonésios e isso facilitava o intercâmbio de informações. Entretanto, a língua tétum, língua nacional de Timor, era igualmente utilizada para tais propósitos - haja visto o fato de que o General Matan Ruak não se comunicava em língua portuguesa e até hoje o faz modestamente - o que possibilita problematizar o enunciado "língua da resistência" na tentativa de entender o que o discurso nele presente apregoa e o que está sendo silenciado. Por conta do prestígio social e de um novo projeto político para o país, o presidente Matan Ruak se vê, então, obrigado a abraçar a ideia de uma lusofonia timorense, somando voz aos discursos oficiais pelo idioma no país.

\section{UMA TENTATIVA DE FINALIZAÇÃO}

Em Timor-Leste, a língua portuguesa foi elemento fundamental para a constituição de uma elite política e intelectual uma vez que, quer seja pelo acesso a informações e ao seu capital cultural, nos tempos coloniais, quer por conta de um projeto de nação que, por questões políticas, buscou um destaque também linguístico no sudeste asiático. Shohami (2006, p.25) destaca que, 
na constituição dos Estados-nação, "a língua tornou-se um dos maiores identificadores da associação, e da inclusão e exclusão, [relativo aos grupos dominantes] e quando os grupos dominantes começam a monopolizar a língua. $" 24$

O capital simbólico relativo à língua portuguesa recebeu um adicional de valor por conta de sua presença no intercâmbio de informações de guerrilha contra a Indonésia, o que contou muito com a atuação de missionários católicos, dado que estes eram os que efetivamente faziam uso do idioma. No período pós-guerra, Timor-Leste organiza o seu projeto de Estadonação, assumindo-se como país independente e buscando autonomia de reconhecimento internacional, estabelecendo fronteiras na região, sobretudo com relação às potências da Indonésia e da Austrália. Para tanto, a associação político-corporativa com a língua portuguesa denuncia a formação de uma nação num viés liberal, o que reforça a importância da categoria "língua" em sua afirmação mundial.

Entretanto, é preciso considerar que a delicada questão da identidade não é contemplada em acordos e programas hegemônicos, que apesar de justificadas por certas "verdades", não evidenciam o sistema simbólico de poder que sustenta o "jogo discursivo" e a construção identitária pretendida (RAJAGOPALAN, 2003). O fato de se estabelecer esforços estatais diversos e benefícios econômicos aos que se inserirem no projeto lusófono timorense, aliado à forte presença da comunidade lusófona internacional no país, traz de volta o prestígio da língua portuguesa numa clara construção simbólica de poderes que fomenta estratificação social, assim como vantagens e privilégios para os que falam sobre os que não falam português.

Apesar das práticas linguísticas cotidianas revelarem distanciamentos dos discursos oficiais $^{25}$, a insistência/persistência do Estado timorense em uma política linguística liberal que, na sua associação a um projeto nacionalista, suprime quase que totalmente as outras línguas nacionais, em vários aspectos suscita ao pensamento de um neocolonialismo com o aval do Estado, no qual "ser timorense", na acepção identitária e cidadã do conceito assumido pelo Estado, dependa cada vez mais do nível de cooptação dos indivíduos a uma invenção linguística lusófona para Timor-Leste, à qual os timorenses são submetidos. Estar fora dessa lusofonia pode significar estar à margem, excluído ou "fora do jogo".

\section{NOTAS}

1 Em malaio, a palavra bahasa significa "língua" 
2 Calvet (2005)

3 Há dois presidentes timorenses do período da guerra de independência que não serão levados em conta nesta análise dado o período conturbado de luta armada em que exerceram o seu "mandato", a saber: Francisco Xavier do Amaral (novembro de 1975 - maio de 1977) e Nicolau dos Reis Lobato (maio de 1977 - dezembro de 1978).

4 Categoria estabelecida oficialmente pelo governo português, através do Estatuto do Indigenato, a partir do Ato Colonial, de 1930, o qual estabelece como "assimilado" os nativos colonizados com comportamento civilizado, convertidos ao catolicismo e que dominavam a língua portuguesa, escrita e falada.

5 http://presidenciarepublica.tl/

6 Decreto Legislativo n. ${ }^{\circ} 12485$, de 13 de outubro de 1926

7 Até o fim do período colonial, Timor contava com o ensino primário, além do Ensino Profissional e o Ensino Agrícola, todos sob a organização da Igreja Católica, ainda que demandados pelo governo português. $\mathrm{O}$ ensino era organizado com separação de sexos e, no Ensino Profissional, os rapazes além de aprenderem os ofícios de serralheiro, carpinteiro, alfaiate e sapateiro, aprendiam também a ler e a escrever. As moças aprendiam a ler, a escrever assim como a costura, lavores e outras artes domésticas. No Ensino Agrícola, destinado apenas aos rapazes, os alunos aprendiam noções teóricas e práticas sobre o cultivo e tratamento de várias culturas (café, borracha, arroz, milho etc), manejo de utensílios agrícolas e pecuária. (MENESES, 2008)

8 Relativamente ao ensino superior, os portugueses não fundaram nenhuma universidade ou outra instituição de ensino superior em Timor. Apenas foram criadas bolsas de estudo destinadas aos estudantes timorenses em 1965 para frequência do ensino superior no exterior, isto é, em Portugal, em Angola e em Moçambique. Contudo, quase só os "assimilados" poderiam aspirar a frequentar o ensino superior $\mathrm{O}$ ingresso no ensino superior, era feito através de um exame de aptidões, que poderia ser realizado em Díli. Em 1974, eram poucos os timorenses com formação superior: "Antes de 1970, apenas dois estudantes por ano frequentavam a Universidade, mas, em 1974, havia 34 alunos a frequentá-la" (TAYLOR, 1993, P.37)

9 Taxas de matrículas e eventuais mensalidades.

${ }^{10}$ Ver também NIXON, Rod. Justice and Governance in East Timor: Indigenous approaches and the "New Subsistence State." New York: Routledge, 2012.

${ }^{11}$ É sabido que Xanana não foi exatamente eleito e assumiu a posição na tentativa de que, na visão dele, houvesse um conflito interno no Comitê Central do partido. O historiador José Mattoso assim descreve a situação, na biografia de outro líder político timorense, Konis Santana: "As leituras, reflexões e memórias acerca de experiências passadas convenceram-no [Xanana] cada vez mais de que a derrota sofrida pelas FALINTIL em 1979 se ficara a dever erros estratégicos resultantes de noções aprendidas nos manuais portugueses de luta colonial, muito apreciados pelo comandante Kilik, nessa altura um dos maiores chefes da guerrilha. Percebeu que não podia esperar a concordância unânime dos seus camaradas, mas que era indispensável unificar o comando, e assumiu as consequências da sua conclusão. " (MATTOSO, 2005, p.90)

${ }^{12}$ DECRETO-LEI N.o 22/2010, de 9 de Dezembro, disponível em file://C:/Users/Alexandre.Xandy/ Downloads/DL\%2023-2010_EstatutoProfessoresSecundario.pdf, acesso em 05.10.2016 / Plano do Ministério da Educação 2013/2017, disponível em http://www.moe.gov.tl/pdf/Plano5anos.pdf, acesso em 05.10.2016

${ }^{13}$ Há, em Díli, a Escola Ruy Cinatti, instituição portuguesa, portanto com uso veicular da língua portuguesa e outras escolas de administração católica que também de alguma forma praticam o idioma. 
${ }^{14}$ Constituição da RDTL, artigos $13^{\circ}$ e $159^{\circ}$

${ }^{15}$ Prêmio Sakharov do Parlamento Europeu (1999); Prêmio da Paz de Kwangju - Coreia do Sul e Prêmio da Paz de Sydney (2000); Prémio da Paz Félix Houphouët-Boigny da UNESCO (2002); Cidadão Honorário de Brasília, Brasil (1995); Ordem da Liberdade, Portugal (1998); Cidadão Honorário de São Paulo, Brasil (1998); Doutoramento Honoris Causa, Universidade Lusíada, Lisboa, Portugal (1999); entre outras diversas homenagens e condecorações.

${ }^{16}$ A mãe e o pai Gusmão, que faziam parte da minúscula elite colonial, baptizaram o primeiro filho com o nome José Alexandre Gusmão e foi por esses nomes que ele foi conhecido até, já adulto, se ter reinventado. Ter diminutivos mais íntimos é um costume timorense. A sílaba do meio de Alexandre, "Xan" é a raiz do diminutivo "Xanana" (...) à procura de um pseudónimo para escrever poesias e artigos na década de 1970, ele adoptou esse diminutivo original e moderno que nunca mais abandonou (NINER, 2011, p.18-19)

${ }^{17}$ Luis Costa , escritor, linguista e dicionarista timorense, em depoimento coletado em 2014, em Díli, quando lá eu trabalhava no âmbito do Programa de Qualificação de Docentes em Língua Portuguesa (PQLP/Capes), explicou que Kay Rala seria o nome do avô de Gusmão usado para homenageá-lo, mas que também cria fortes laços com as tradições familiares timorenses em suas adorações aos antepassados (chamados de matebian). Segundo Costa, "Xanana também adoptou o nome indígena do avô materno, Kay Rala, seguindo o exemplo de muitos jovens nacionalistas que reclamaram a sua ascendência indígena." Luis Costa acrescenta ainda que, na língua Galolen, falada na região de origem de Gusmão, Kay Rala significa Raio Mal (perigoso) o que possui um efeito intimidante junto aos inimigos (indonésios).

${ }^{18}$ Nas próprias palavras de Horta, "Ao contrário do Camboja que foi manchete em todo o mundo quando foi invadido pelo Vietname, a carnificina de Timor Leste tem sido quase completamente ignorada. Com algumas excepções honrosas, quase todos os Governos do mundo optaram pelo silêncio. Disponível em http://www3.dsi.uminho.pt/academiamilitar/1999/prsnldds/perstimr/horta.htm, acesso em 15.02.2016

${ }^{19}$ Dentre os principais prêmios recebidos, estão: Prémio Ativista Internacional, Fundação Gleitsman (CA), E.U.A (1995); Prémio de Direitos Humanos Professor Thorof Rafto, Alemanha (1993); GrãCruz da Ordem da Liberdade, Portugal (1998); Medalha da Universidade de São Francisco, CA, E.U.A (1997); Prémio Apelo à Paz de Haia, Holanda (1999); Medalha de Ouro da Universidade de Coimbra, Portugal (1998); Medalha de Ouro do Presidente da Itália (2000). Assim como Gusmão, escreveu diversos livros como Construir a Paz - Discursos e Intervenções - Volume I, Sou o Futuro, Funu the Unfinished Saga of East Timor (em inglês), Timor Leste Amanhã em Díli e Para o ano em Jerusalém.

${ }^{20}$ Disponível em https://www.youtube.com/watch?v=4EVjn7Pye_o, acesso em 10.02.2016.

${ }^{21}$ Revista Camões no 14,2001 , disponível em http://cvc.instituto-camoes.pt/conhecer/biblioteca-digitalcamoes/revistas-e-periodicos/revista-camoes/revista-no14-timor-lorosae.html , acesso em 05.10.2016

${ }^{22}$ Reportagem disponível em http://observalinguaportuguesa.org/taur-matan-ruak-discursou-em-portugu es -na-recepcao-ao-presidente-da-republica-da-indonesia/, acesso em 13.02.2016.

${ }^{23}$ Matan Ruak não escreveu livros, mas teve alguns de seus discursos publicados no livro Cidadania para o Desenvolvimento, publicado em 2013 pela editora Lidel, com textos traduzidos para o português.

24 “(...)language became one of the main identifiers of membership, ando $f$ inclusion and exclusion, and when the ruling groups started monopolizing language."(tradução livre minha)

${ }^{25}$ Ver Brito; Dias; Silveira (2016) 


\section{REFERÊNCIAS}

ALKATIRI, Mari. Timor-Leste: o caminho do desenvolvimento. Os primeiros anos de governação. Lisboa: Lidel, 2012.

ANJOS, José Carlos Gomes. Intelectuais, literatura e poder em Cabo Verde. Porto Alegre: UFRGS, 2006.

BOURDIEU, Pierre. Campo de poder, campo intelectual. Buenos Aires: Folios, 1983.

BOURDIEU, Pierre. Sobre o Estado. São Paulo: Companhia das Letras, 2015.

CARRASCALÃO, Maria Ângela. Taur Matan Ruak: a vida pela independência. Lisboa: Lidel, 2012.

CODATO, Adriano. Introdução: estudos de elites, uma nota metodológica. In: CODATO, A.; KIELLER, M. Velhos vermelhos: história e memória dos dirigentes comunistas no Paraná. Curitiba: UFPR, 2008.

CORADINI, O. L. Em nome de quem? Recursos sociais no recrutamento de elites políticas. Rio de Janeiro: Relume-Dumará, 2001.

DALLABRIDA, N. A fabricação escolar das elites: o Ginásio Catarinense na Primeira República. Florianópolis: Cidade Futura, 2001.

EMBAIXADA DE TIMOR-LESTE. Biografia oficial dos presidentes da República Democrática de Timor-Leste.

HEINZ. Flavio M. Nota sobre o uso de anuários sociais do tipo Who's who em pesquisa prosopográfica. In: HEINZ, Flavio M. (org) História social de elites. São Leopoldo: Oikos, 2011.p.154-165

MATTOSO, José. A Dignidade: Konis Santana e a Resistência Timorense. Lisboa: Temas e Debates, 2005.

MENESES, Duarte Nuno de Castro. Timor - De Colónia a País nos fins do século XX: Um sistema educativo em Re-estruturação. (Um estudo documental). Porto: Universidade D. Henrique, 2008.

MICHELS, Robert. Para uma sociologia dos partidos políticos na democracia moderna: investigação sobre as tendências oligárquicas na vida dos agrupamentos políticos. Lisboa: Antígona, 1971.

MILLS, C. Wright. A Elite do Poder. Rio de Janeiro: Zahar, 1959.

MONTEIRO, Lorena. Estudos de elites políticas e sociais: as contribuições da Sociologia e da História. Sociedade e Cultura, Goiânia, v. 12, n. 1, p. 25-32, jan./jun. 2009

MOSCA, Gaetano. The Ruling Class, New York: McGraw-Hill Paperbacks, 1963. 
NINER, Sara. Xanana - Líder da luta pela independência de Timor-Leste. Alfragide: Dom Quixote, 2011

PARETO, Vilfred. Manual de Economia Política, Rio de Janeiro: Fundo de Cultura, 1963.

SAINT MARTIN, M. de. Da reprodução às recomposições das elites: as elites administrativas, econômicas e políticas na França. TOMO (UFS), n. 13, 2008.

SEIDL, E. Estudar os poderosos: a sociologia do poder e das elites. In: SEIDL, E; GRILL, I. G. (org.). As Ciências Sociais e os espaços da política no Brasil. Rio de Janeiro: Editora FGV, 2013.

TAYLOR, John G. Timor - A História Oculta. Venda Nova: Bertrand Editora, 1993 